\title{
Long-term follow-up in optimally treated and stable heart failure patients: primary care vs. heart failure clinic. Results of the COACH-2 study
}

Marie Louise A. Luttik, Tiny Jaarsma, Peter Paul van Geel, Maaike Brons, Hans L. Hillege, Arno W. Hoes, Richard de Jong, Gerard Linssen, Dirk J. A. Lok, Marjolein Berge and Dirk J. van Veldhuisen

\section{Linköping University Post Print}

\section{Tweet}

N.B.: When citing this work, cite the original article.

Original Publication:

Marie Louise A. Luttik, Tiny Jaarsma, Peter Paul van Geel, Maaike Brons, Hans L. Hillege, Arno W. Hoes, Richard de Jong, Gerard Linssen, Dirk J. A. Lok, Marjolein Berge and Dirk J. van Veldhuisen, Long-term follow-up in optimally treated and stable heart failure patients: primary care vs. heart failure clinic. Results of the COACH-2 study, 2014, European Journal of Heart Failure, (16), 11, 1241-1248.

http://dx.doi.org/10.1002/ejhf.173

Copyright: Oxford University Press (OUP)

http://www.oxfordjournals.org/

Postprint available at: Linköping University Electronic Press

http://urn.kb.se/resolve?urn=urn:nbn:se:liu:diva-112816 


\section{Long term follow-up in optimally treated and stable Heart Failure patients; Primary Care versus Heart Failure Clinic. Results of the COACH-2 study}

\section{Authors}

Marie Louise A. Luttik, RN, $\mathrm{PhD}^{1}$

Tiny Jaarsma, $\mathrm{RN}, \mathrm{PhD}^{2}$

Peter Paul van Geel, MD, $\mathrm{PhD}^{1}$

Maaike Brons, $\mathrm{RN}, \mathrm{MSc}^{3}$

Hans L. Hillege, MD $\mathrm{PhD}^{1}$

Arno W. Hoes, MD PhD ${ }^{4}$

Richard de Jong, $\mathrm{MD} \mathrm{PhD}^{5}$

Gerard Linssen, $\mathrm{MD}, \mathrm{PhD}^{6}$

Dirk J.A. Lok, MD, $\mathrm{PhD}^{7}$

Marjolein Berger, $\mathrm{MD} \mathrm{PhD}^{8}$

Dirk J. van Veldhuisen, MD PhD ${ }^{1}$

1 Department of Cardiology, University Medical Center Groningen/University of Groningen, the Netherlands

2 ISV, Department of Social and Welfare Studies, Faculty of Health Sciences, Linköping, Sweden

3 Department of Cardiology, University Medical Center Utrecht, Utrecht, the Netherlands

4 Julius Center for Health Sciences and Primary Care, University Medical Center Utrecht, the Netherlands

5 Department of Cardiology, Wilhelmina Ziekenhuis Assen, the Netherlands

6 Department of Cardiology, Ziekenhuisgroep Twente, Almelo and Hengelo, the Netherlands

7 Department of Cardiology, Stichting Deventer Ziekenhuizen, Deventer, the Netherlands

8 Department of General Practice Medicine, University Medical Center Groningen, University of Groningen, The Netherlands 


\section{Corresponding Author}

Dr. M.L.A. Luttik

Department of Cardiology

University Medical Center Groningen

University of Groningen

PO BOX 30.001

9700 RB Groningen

The Netherlands

Tel. $\quad 31503610541$

Fax. $\quad 31503614391$

E-mail: m.l.a.luttik@umcg.nl

Key words; heart failure, primary care, disease management, adherence

Word count; 3320 


\section{Abstract}

\section{Aim}

It has been suggested that home-based Heart Failure (HF) management in primary care may be an alternative to clinic-based management in HF patients. However, little is known about adherence to HF guidelines and adherence with the medication regimen in these home-based programmes. The aim of the current study was to determine whether long-term follow-up and treatment in primary care is equally effective as follow-up at a specialized HF clinic in terms of guideline adherence and patient adherence, in HF patients initially managed and up-titrated to optimal treatment at a specialized HF clinic.

\section{Method and Results}

We conducted a multi-centre, randomized, controlled study in 189 HF patients (62\% male, age $72 \pm 11$ yrs), who were assigned to either follow-up in primary care $(n=97)$ or in a HF clinic ( $\mathrm{n}=92$ ). After 12 months, no differences between guideline adherence, as estimated by the Guideline Adherence Indicator (GAI-3), and patient adherence, in terms of the medication possession ratio (MPR), were found between treatment groups. There was no difference in the number of deaths ( $n=12$ in primary care, and $n=8$ in the HF clinic; $p=0.48)$, and hospital readmissions for cardiovascular $(\mathrm{CV})$ reasons were also eomparablesimilar. The total number of unplanned non-CV hospital readmissions, however, tended to be higher in the primary care group ( $n=22)$ than in the HF clinic group $(n=10 ; p=0.05)$.

\section{Conclusion}

Patients discharged after initial management in a specialized HF clinic can be discharged to primary care for long-term follow-up with regard to maintaining guideline adherence and patient adherence. However, the complexity of the HF syndrome and its associated co morbidities, requires continuous monitoring. Close collaboration between health care providers in the different echelons-will be crucial in order to provide HF with optimal, 
integrated care. 


\section{Introduction}

Although treatment of heart failure (HF) has improved in the past decades with the development of multiple medications and devices, mortality and morbidity are still considerable. ${ }^{1,2}$ In addition to optimal medical management, the HF guidelines ${ }^{3}$ recommend to enrol HF patients in a multidisciplinary-care management including follow-up after discharge (by visits, telephone support or remote monitoring). An important issue is whether long-term management of HF patients must remain under the care of a HF clinic (in a hospital), or whether patients can be referred back to the general practitioner (GP) to be further managed in the primary care setting. There is little documentation and limited evidence suggesting that follow-up in primary care assures successful continuation of evidence-based therapy. Moreover, the study of Ojeda and colleagues ${ }^{4}$ showed that after ending an intervention program, the results of the initial optimization and education decreased within the next year ${ }^{4}$ Clearly, if such a home-based programme in primary care would be similarly effective, this would have large clinical, practical and economic advantages. However, the optimal model for the delivery of long term multidisciplinary-care management is still unknown., 5

Recent large-scale studies show that not all models are equally successful to improve outcomes and they indicate that a tailored approach to HF management is needed. ${ }^{7,8}$ The WHICH? trial which was conducted in Australia indicated that a home-based HF management programme was equally effective in terms of outcome, and associated with lower healthcare costs as to an equivalent clinic-based programme. ${ }^{9}$ In the much larger Danish NorthStar study, it was shown that stable HF patients on optimal therapy did not benefit from long-term follow-up in a specialized HF clinic, and indeed, they could be referred back safely to their GP. ${ }^{10}$ 
Although these studies reported baseline medication, they did not examine whether guideline recommended HF medication was continued throughout the study. This is important since it has been shown that guideline adherence in HF patients primarily treated by their GP is lower than in patients treated by cardiologists, which may, at least be partly attributable to the fact that GPs usually deal with older patients with more co-morbidity. ${ }^{11-13}$ GPs seem to experience barriers in the initiation and optimization of pharmacological treatment. ${ }^{14}$ Little is known about the long term adherence to HF guidelines, after initial optimization of medication. Patient compliance, nowadays knows as patient adherence, is an important predictor of outcome in $\mathrm{HF}^{15,16}$ and patients often have difficulty to remain compliant to treatment in the long run. ${ }^{4}$ The role of patient adherence to guideline therapy in home-based management programmes has not been studied yet.

We therefore designed the (Comparative study On guideline Adherence and patient Compliance in Heart failure patients $(\mathrm{COACH}-2)$ study ${ }^{17} \mathrm{COACH}-2$ study aimed to determine whether long-term follow-up in primary care can be equally effective as compared to follow-up in a specialized HF clinic in terms of guideline adherence to the guideline recommended HF medication and patient adherence with medication with these recommendations.

\section{Methods}

\section{Study design}

The $\mathrm{COACH}-2$ study was a multi-centre, non-inferiority, randomized, controlled trial and a detailed description of its rationale and design has been published previously. ${ }^{17} \mathrm{COACH}-2$ trial was approved by the Central Ethics Committee of the University Hospital Groningen and performed according to The Helsinki Declaration. The study is listed in the Netherlands Trial Register (NTR1729). 


\section{Study patients}

Patients were recruited from 4 outpatient HF clinics in the Netherlands. HF clinics were all settled in hospitals delivering specialized consultative health care, in a facility with personnel and facilities for advanced medical investigation and treatment. All visiting patients were screened for their eligibility to participate in the study. Patients were eligible if they: 1) had documented symptoms of HF (either currently or at time of diagnosis), 2) HF with evidence for structural underlying ventricular dysfunction (LVEF $<45 \%$ at time of diagnosis), 3) were up-titrated to optimal pharmacological treatment; AngiotensinConverting-Enzyme Inhibitor (ACE-I ) / Angiotensin Receptor Blockers (ARB), betablockers and mineralocorticoid (aldosterone) receptor antagonists (MRAs) for NYHA III patients according the ESC guidelines of $2008^{18}$, 4) clinically stable for at least 1 month, i.e. no hospital admission in the previous month, no visits to the emergency unit for decompensated HF in the previous month and no unplanned medication changes in the previous month, 5) optimally educated and informed about HF and required lifestyle changes and 6) 18 years or older.

Exclusion criteria included 1) management by a cardiologist planned for diagnostics or if additional treatment was needed according to the cardiologist or GP, 2) the GP had substantial arguments against patient participation in the study, 3) the patient was unable to fill in data collection materials, 4) the patient had a life expectancy $<6$ months, 5) the patient was living in a nursing home or 6) the patient had a current psychiatric disorder.

\section{Study procedure}

Patients and their caregivers were informed about the study when visiting the outpatient HF clinic in one of the participating centres. Thereafter, patients were titrated to optimal, guideline recommended HF medication and were educated about HF, its treatment and 
lifestyle changes. After being titrated to optimal HF medication and confirmed stable for at least 4 weeks, patients were approached to participate in the study and to give their informed consent. Patients were then randomly allocated to follow-up by their GP (PC group) or follow-up by the HF clinic (HF clinic group). GPs were randomly selected following the randomization of patients and were not specifically trained for this study. Contacts and visits in both groups were assumed to take place according to the European Guidelines for treatment of acute and chronic heart failure ${ }^{18}$ and according to the Dutch Multidisciplinary Guideline on Chronic Heart Failure. ${ }^{19}$ Within the HF clinic group, contact with the GP was possible following the 'care as usual' principle. Within the PC group no visits at the HF clinic were scheduled, however consultation of the HF clinic by the GP was possible. At the end of the follow-up period (12 months), all patients from both treatment groups were invited to an end of study visit at the HF clinic.

\section{Study outcomes}

This study had two primary outcomes, guideline adherence and patient adherence. It was hypothesized that long-term follow-up under the described conditions, would be equally effective in both groups in terms of guideline adherence and patient compliance at1 year follow-up. Guideline adherence was measured by means of the Guideline Adherence Indicator (GAI) ${ }^{20}$, including guideline recommended prescription of ACE-I (or ARB) and Beta-blocker for all patients and spironolactone in patients with NYHA $\geq$ III . Guideline adherence for the primary end point was defined as a GAI of $100 \%$. The other primary endpoint was patient adherence with medication in terms of the medication possession ratio (MPR) calculated from digital pharmacy records over 12 months of follow-up. The MPR reflects the number of days that prescribed medication was available for patients based on their drug refill behaviour following the prescribed medications. ${ }^{21}$ 
Medication that started after randomization was not included, unless it was a switch between drugs within the same therapeutic class. Patients who died during follow up $(n=20)$ and patients that had their drugs weekly delivered automatically by a multi-dose medication dispense system $(n=31)$ were excluded from the analyses. For 17 patients, pharmacy data were missing or incomplete. Secondary outcomes included mortality and readmission rates. The researchers adjudicated hospital readmissions based on the medical records and blinded for group assignment.

\section{Statistical analysis}

The trial was powered for a non-inferiority comparison for guideline adherence. Noninferiority for guideline adherence was considered proven if the lower limit of the 1-sided 95\% CI of the difference between adherence during the GP follow-up and the HF clinic follow-up did not exceed a margin of $20 \%$. In total 75 patients randomized to receive standard care and 75 patients to receive primary care are needed to demonstrate noninferiority assuming a standard care guideline adherence rate of $60 \%$ and a power of $80 \%$. Categorical variables, including the primary endpoint, were compared with the chi-square test or Fisher's exact test, where appropriate. Continuous data were presented as a mean \pm SD or median plus interquartile range (IQR), depending on the distribution of the data. MannWhitney $U$ tests were used for comparison of non-normally distributed continuous data and Student $t$ test for normally distributed continuous data. The analysis of the secondary primary endpoint, patient adherence, was performed by using the Mann Whitney $U$ test for nonnormally distributed percentages or medication possession ratio's. Incidence rates and incidence rate differences per year were determined for death and readmissions per treatment group. A $p$-value of $<0.05$ was considered statistically significant.

Statistical analyses were performed using SPSS, Chicago version 12.0 and STATA, 
College Station, Texas, version 12.1 on an intention to treat basis.

\section{Results}

\section{Patients}

A total of 419 patients met the inclusion criteria (Figure 1). Of these, 230 were not willing to participate for various reasons such as 'not willing to be referred to their GP' (n=160), 'not willing to visit the HF clinic' ( $\mathrm{n}=12)$, 'participation too stressful' ( $\mathrm{n}=34)$, 'refusal to participate in research studies' $(n=21)$, and other reasons $(n=3)$. The remaining 189 patients were the present study population, and they were randomized to either follow-up in primary care $(n=97)$ or follow-up at the HF clinic $(n=92)$.

The mean age of the patients was $72 \pm 11$ years, and they were predominantly male (62\%) and were mainly classified as NYHA II or III at baseline. Co-morbidities such as diabetes, COPD and atrial fibrillation were common and there were no significant differences in baseline characteristics between the groups (Table 1).

\section{Primary endpoints}

\section{Guideline Adherence}

Since titration to optimal, guideline recommended medication was an inclusion criterion, guideline adherence at baseline was high with $90 \%$ and $87 \%$ in the PC and HF clinic group respectively. Guideline recommended medication rates were high with $90 \%$ and $92 \%$ of patients having an ACE-I or ARB prescribed in the PC and HF clinic group respectively.

Primary care, as compared with follow-up at the HF clinic, resulted in similar rates of guideline adherence at 12 months follow-up $(81 \%$ and $80 \%$, respectively; difference, $1.0 \%$; $95 \%$ CI, $-10 \%$ to $12 \% ; P$ for non-inferiority <.001). In total $94 \%$ and $90 \%$ of patients had a 
beta-blocker prescribed in the PC and HF clinic group respectively and $43 \%$ and $53 \%$ of patients had an MRA prescribed in the PC and HF clinic group respectively. Prescription rates at 12 months follow-up were eemparable-similar with baseline rates (Table 2)

Guideline adherence, as estimated by the Guideline Adherence Indicator (GAI-3), did not show significant differences between both treatment groups at baseline nor at 12 months follow-up (Table 2 and 3).

\section{$\underline{\text { Patient adherence }}$}

Medication Possession Ratio (MPR) was calculated per therapeutic class (ACE-I/ARB, betablocker and MRA) using a fixed 1-year period (365 days) following date of randomisation. Analyses of patient adherence data is based on 120 patients (Table 4). Patients who died during follow up $(\mathrm{n}=20)$ and patients that had their drugs weekly delivered automatically by a multi-dose medication dispense system $(n=31)$ were excluded from these analyses. For 18 patients, pharmacy data were missing or incomplete. During follow-up, no significant differences between patients in the PC group and patients in the HF clinic group were found for any of the medication classes nor for the average total score. Patient adherence in terms of MPR was high for both ACE-I/ARB (93.5\% and 95.2\% in the PC group and HF clinic group respectively) and beta-blockers (93.5\% and $94.9 \%$ in the PC group and HF clinic group respectively). Patient adherence for MRA was $87.1 \%$ in the PC group and $93.3 \%$ in HF clinic group.

\section{$\underline{\text { Secondary outcomes }}$}

During the 12 months follow-up period 20 patients died, 12 (12\%) in the PC group and 8 (9\%) in the HF clinic group ( $\mathrm{p}=0.48$ ). In total 42 patients had an unplanned rehospitalisation within 12 months, 25 patients in the PC group and 17 patients in the HF clinic, resulting in a 
total of 58 unplanned hospital readmissions, with 13 patients being hospitalized more than once (Table 5). Readmissions for HF and other cardiovascular reasons were eomparable similar in both treatment groups ( 8 vs 7 for $\mathrm{HF}$ and 5 vs $6 \mathrm{CV}$ reasons in the PC group versus the HF clinic group respectively).

The number of unplanned non-CV hospital readmissions tended to be higher in the PC group with 22 versus 10 readmissions in the HF clinic group $(\mathrm{p}=0.05)$. Some patients had more than one non-CV readmission, and the difference in number of patients readmitted between both groups was not significant ( $\mathrm{p}=0.09$ ). Reasons for these non-CV hospital readmissions in both treatment groups are presented in table 6.

\section{Discussion}

The COACH-2 study compared guideline adherence and patient adherence in two different HF care delivery models, i.e. home-based management by the general practitioner in primary care versus hospital-based management in a HF clinic, in patients initially managed and uptitrated to optimal treatment at the specialized HF clinic. The main finding of the study is, that after initial uptake and optimization of HF treatment in a specialized HF clinic, long-term follow-up by general practitioners in primary care is eomparablesimilar, i.e. non-inferior in terms of guideline adherence and adherence with medication in patients. During follow-up, the number of deaths as well as the number of hospitalizations for CV were comparable similar between groups, while the number of non-CV hospitalizations tended to be higher $(\mathrm{p}=0.05)$ in the primary care group.

The present findings are in line with the results of the NorthStar study ${ }^{10}$, which showed that clinically stable HF patients, on optimal medical therapy can be safely referred back to follow-up in primary care in terms of mortality and HF readmissions. The current 
study provides additional evidence in that long term follow-up at a HF clinic does not lead to a benefit in terms of guideline adherence and patient adherence in clinically stable patients with mild to moderate HF.

Despite optimal treatment and presumed clinical stability, 20 out of 189 patients died within a year and 58 unplanned hospital admissions occurred. More than half (55\%) of these hospitalizations were for non-CV reasons which is in line with the results of the first $\mathrm{COACH}$ study. ${ }^{7}$ Importantly, we observed more non-CV hospital admissions in the primary care group compared to the HF clinic group, although this was of borderline statistical significance. This relatively high number of non-CV hospitalizations confirm the complexity of the $\mathrm{HF}$ syndrome, which is associated with a large number of co morbidities, particularly in the elderly. ${ }^{22,23}$ Although non-significant, baseline differences between both treatment groups e.g. the prevalence of diabetes may have influenced the difference in non CV hospitalisations. Along with these multiple co morbidities, the clinical course of HF patients is often unpredictable with clinically stable phases interspersed with periods of exacerbation and deterioration finally ending in a terminal phase. ${ }^{24}$ Over time, patients' needs, treatment and care may become more complex, often requiring regular adjustments. Continuous monitoring of the patients' condition is therefore needed and intensive collaboration between primary care and specialized HF care will be crucial in these phases to determine how and where best treatment and care can be provided according to the patient's needs. The ultimate goal, as described by the ESC Heart Failure Association ${ }^{22}$, can be described as 'to provide a "seamless" system of care across primary care and hospital care so that management of every patient is optimal, no matter where they begin or continue their health care journey'.

There are potential limitations to the present findings. First, the number of patients enrolled is relatively small and was not powered to detect significant differences in terms of mortality nor the number of hospitalizations. Secondly, it is important to notice that the 
generalizability of our study results is limited to the specific conditions that were applied within in the COACH-2 study. The study included clinically stable patients with systolic dysfunction who were optimally treated and educated at a specialized HF clinic, mainly classified as NYHA class II, who were followed for a period of 12 months. Whether our conclusion is also generalizable on a longer term and to more severe HF patients remains to be established. Furthermore, a substantial number of patients did not want to participate in the study, mainly because of their preference to receive follow-up care at the HF clinic. This finding may have biased our study population towards patients that are willing to be treated in primary care. Interestingly, this phenomenon was also reported by Stewart et al. ${ }^{9}$ in the WHICH? trial. Since it is acknowledged that patient preferences are vital in delivering optimal health care ${ }^{25}$, patient's preferences for a specific delivery model of HF care may be an important dilemma in terms of delivering the patient's choice of care on the one hand versus cost effectiveness on the other hand. Finally, as far as the applicability of our findings to other countries is concerned, health care in the Netherlands is known as a primary carebased system where the GP acts as the gate-keeper for secondary care and where patients can consult their GP with only limited costs involved ${ }^{26}$. This low threshold may generally be advantageous, but it cannot be excluded that some patients in the present study who were in the HF clinic group, also consulted their GPs when they felt that was necessary. General practitioners are well educated, working with high quality guidelines for many chronic diseases including HF. ${ }^{19}$ European practice guidelines are endorsed by the different echelons of health care professionals in the Netherlands. These conditions may be different in other countries with other health care systems; results may therefore not be generalized to countries with other health care- and educational systems. 


\section{Conclusion}

Patients discharged after initial management, up-titration and education at a specialized HF clinic can be discharged to primary care for long-term follow-up with regard to maintaining guideline adherence and patient adherence. This study investigated the first step in optimizing the structural involvement of the GP in long-term HF management. The uptake of treatment and up-titration of medication by GPs in primary care could be a next step that needs further research. The complex clinical picture of $\mathrm{HF}$ and the high number of associated co morbidities needs continuous monitoring. Moreover, close collaboration between healthcare professionals will remain crucial to provide HF patients with integrated, optimal HF care that best fits patients in the different phases of their disease trajectory. 


\section{Acknowledgements}

We would like to thank dr. P. Denig and the department of Clinical Pharmacology of the University Medical Centre Groningen, Groningen, the Netherlands for computing Medication Possession Ratios and their assistance in the interpretation of the results regarding patient adherence.

Furthermore, we would like to thank all contributors to the COACH-2 study, especially HF nurses in the participating centres, for providing the data for this study.

\section{Funding}

The COACH-2 study was funded by the Netherlands Heart Foundation (NHF) within one of their research programs (2008B083).

\section{Conflict of interest}

None to declare 


\section{Reference List}

(1) Chen J, Normand SL, Wang Y, Krumholz HM. National and regional trends in heart failure hospitalization and mortality rates for Medicare Beneficiaries. 1998-2008. JAMA 2011;306:1669-1678.

(2) McAlister FA, Stewart S, Ferrua S, McMurray JJ. Multidisciplinary strategies for the management of heart failure patients at high risk for admission. A systematic review of randomized trials. J Am Coll Cardiol 2004; 44:810-819.

(3) McMurray JJ, Adamopoulos S, Anker SD, Auricchio A, Bohm M, Dickstein K, Falk V, Filippatos G, Fonseca C, Gomez-Sanchez MA, Jaarsma T, Køber L, Lip GY, Maggioni AP, Parkhomenko A, Pieske BM, Popescu BA, Rønnevik PK, Rutten FH, Schwitter J, Seferovic P, Stepinska J, Trindade PT, Voors AA, Zannad F, Zeiher A; ESC Committee for Practice Guidelines. ESC Guidelines for the diagnosis and treatment of acute and chronic heartfailure 2012: The Task Force for the Diagnosis and Treatment of Acute andChronic Heart Failure 2012 of the European Society of Cardiology. Developed in collaboration with the Heart Failure Association (HFA) of the ESC. Eur Heart J 2012;33: 1787-847 .

(4) Ojeda S, Anguita M, Delgado M, Atienza F, Rus C, Granados AL, Ridocci F, Vallés F, Velasco JA. Short- and long-term results of a programme for the prevention of readmissions and mortality in patients with heart failure: are effects maintained after stopping the programme? Eur J Heart Fail 2005;7:921-926.

(5) Stewart S. What is the optimal place for heart failure treatment and care: home or hospital? Curr Heart Fail Rep 2013;10:227-231. 
(6) McAlister FA, Bakal JA, Kaul P, Quan H, Blackadar R, Johnstone D, Ezekowitz J. Changes in heart failure outcomes after a province-wide change in health service provision. A natural experiment in Alberta, Canada. Circ Heart Fail 2013;6:76-82.

(7) Jaarsma T. van der Wal MH, Lesman-Leegte I, Luttik ML, Hogenhuis J, Veeger NJ, Sanderman R, Hoes AW, van Gilst WH, Lok DJ, Dunselman PH, Tijssen JG, Hillege HL, van Veldhuisen DJ; Coordinating Study Evaluating Outcomes of Advising and Counseling in Heart Failure (COACH) Investigators. Effect of moderate or intensive disease management program on outcome in patients with heart failure: Coordinating Study Evaluating Outcomes of Advising and Counseling in Heart Failure (COACH). Arch Intern Med 2008; 11:316-324.

(8) Powell LH, Calvin JE Jr, Richardson D, Janssen I, Mendes de Leon CF, Flynn KJ, Grady KL, Rucker-Whitaker CS, Eaton C, Avery E; HART Investigators. Selfmanagement counseling in patients with heart failure: the heart failure adherence and retention randomized behavioral trial. JAMA 2010;304:1331-1338.

(9) Stewart S, Carrington MJ, Marwick TH, Davidson PM, MacDonald P, Horowitz JD, Krum H, Newton PJ, Reid C, Chan YK, Scuffham PA. Impact of Home Versus ClinicBased Management of Chronic Heart Failure. J Am Coll Cardiol 2012;60:1239-1248

(10) Schou M, Gustafsson F, Vedebaeck L. Tuxen C, Keller N, Sejr Knudsen A, Espersen G, markenvard J, Egstrup K, Ulriksen H, Hildebrandt PR. Extended heart failure clinic follow-up in low-risk patients: a randomized clinical trial (NorthStar). Eur Heart J 2013;34:432-442.

(11) Cleland JG, Cohen-Solal A, Aguilar JC, Dietz R, Eastaugh J, Follath F, Fremantle N, Gavazzi A, van Gilst WH, Hobbs FD, Korewicki J, Madeira HC, Preda I, Swedberg K, Widimsky J. Management of heart failure in primary care (the IMPROVEMENT of Heart Failure Programme): an international survey. Lancet 2002;360:1631-1639. 
(12) Bosch M, Wensing M, Bakx JC, van der Weijden T, Hoes AW, Grol RPTM. Current treatment of chronic heart failure in primary care; still room for improvement. $J$ Eval Clin Pract 2010;16:644-650.

(13) Dahlstrom U, Hakansson J, Swedberg K, Waldenstrom A. Adequacy of diagnosis and treatment of chronic heart failure in primary health care in Sweden. Eur J Heart Fail 2009;11:92-98.

(14) Kasje WN, Denig P, de Graeff PA, Haaijer-Ruskamp FM. Perceived barriers for treatment of chronic heart failure in general practice; are they affecting performance? BMC Fam Pract 2005;6:19.

(15) Wu JR, Lennie TA, Dekker RL, Biddle MJ, Moser DK. Medication adherence, depressive symptoms and cardiac event-free survival in patients with heart failure. $J$ Card Fail 2013;19:317-324.

(16) Riegel B, Knafl GJ. Electronically monitored medication adherence predicts hospitalization in heart failure patients. Patient Prefer Adherence 2013;5:1-13.

(17) Luttik ML, Brons M, Jaarsma T, Hillege HL, Hoes A, de Jong R, Linssen G, Lok DJ, Berger M, van Veldhuisen DJ. Design and methodology of the COACH-2 (Comparative study on guideline adherence and patient compliance in heart failure patients) study: HF clinics versus primary care in stable patients on optimal therapy. Neth Heart J 2012;20:307-312

(18) Dickstein K, Cohen-Solal A, Filippatos G, McMurray JJ, Ponikowski P, Poole-Wilson PA, Strömberg A, van Veldhuisen DJ, Atar D, Hoes AW, Keren A, Mebazaa A, Nieminen M, Priori SG, Swedberg K. ESC guidelines for the diagnosis and treatment of acute and chronic heart failure 2008: the Task Force for the diagnosis and treatment of acute and chronic heart failure 2008 of the European Society of Cardiology. Developed in collaboration with the Heart Failure Association of the ESC (HFA) and 
endorsed by the European Society of Intensive Care Medicine (ESICM). Eur J Heart Fail 2008;10:933-989

(19) NHG standaard Hartfalen; eerste herziening. Huisarts en Wetenschap 2009;48:64-76.

(20) Komajda M, Lapuerta P, Hermans N, Gonzalez-Juanatey JR, van Veldhuisen DJ, Erdmann E, Tavazzi L, Poole-Wilson P, Le Pen C. Adherence to guidelines is a predictor of outcome in chronic heart failure: the MAHLER survey. Eur Heart J. 2005; 26:1653-1659.

(21) Vink NM, Klungel OH, Stolk RP, Denig P. Comparison of various measures for assessing medication refill adherence using prescription data. Pharmacoepidemiol Drug Saf 2009;18:159-165.

(22) McDonagh TA, Blue L, Clark AL, Dahlström U, Ekman I, Lainscak M, McDonald K, Ryder M, Strömberg A, Jaarsma T. European Society of Cardiology Heart Failure Association. Standards for delivering heart failure care. Eur J Heart Fail 2011;13:235241.

(23) Van Veldhuisen DJ, Linssen GCM, Jaarsma T, van Gilst WH, Hoes AW, Tijssen JGP, Paulus WJ, Voors AA, Hillege HL. B-Type Natriuretic Peptide and Prognosis in Heart Failure patients with Preserved and Reduced Ejection Fraction. J am Coll Cardiol 2013;61:1498-1506.

(24) Kheirbek RE, Kheirbek RE, Alemi F, Citron BA, Afaq MA, Wu H, Fletcher RD. Trajectory of illness for patients with congestive heart failure. J Palliat Med 2013;16:478-484.

(25) Spertus JA. Evolving applications for patient-centered health status measures. Circulation 2008;118:2103-2310 
(26) Bruggink-Andre de la Porte PW, Lok DJ, van Veldhuisen DJ, van Wijngaarden J, Cornel JH, Zuithoff NP, Badings E, Hoes AW. Added value of a physician-and-nursedirected heart failure clinic: results from the Deventer-Alkmaar heart failure study. Heart 2007;93:819-82 
Table 1. Baseline characteristics per treatment group (mean/sd or $\mathbf{n} / \%)$

\begin{tabular}{|c|c|c|}
\hline & $\begin{array}{c}\text { Primary Care } \\
(n=97)\end{array}$ & $\begin{array}{c}\text { HF clinic } \\
(n=92)\end{array}$ \\
\hline \multicolumn{3}{|l|}{ Demographics } \\
\hline Age & $73( \pm 10)$ & $72( \pm 12)$ \\
\hline Gender (female) & $36(37 \%)$ & $36(39 \%)$ \\
\hline \multicolumn{3}{|l|}{ Medical History } \\
\hline Myocardial Infarction (MI) & $43(44 \%)$ & $35(38 \%)$ \\
\hline Diabetes (type I and II) & $28(29 \%)$ & $15(16 \%)$ \\
\hline COPD & $18(19 \%)$ & $17(18 \%)$ \\
\hline History of Atrial Fibrillation & $45(46 \%)$ & $33(36 \%)$ \\
\hline Admission in past 6 months & $10(10 \%)$ & $7(8 \%)$ \\
\hline \multicolumn{3}{|l|}{ Heart Failure/Clinical } \\
\hline $\begin{array}{l}\text { NYHA class } \\
\text { NYHA I } \\
\text { NYHA II } \\
\text { NYHA III } \\
\text { NYHA IV }\end{array}$ & $\begin{array}{l}12(12 \%) \\
75(77 \%) \\
10(10 \%) \\
-\end{array}$ & $\begin{array}{c}7(8 \%) \\
69(75 \%) \\
16(17 \%) \\
-\end{array}$ \\
\hline $\begin{array}{c}\text { Blood pressure }(\mathrm{mmHG}) \\
\text { Systolic } \\
\text { Diastolic }\end{array}$ & $\begin{array}{c}119( \pm 16) \\
69( \pm 9)\end{array}$ & $\begin{array}{l}120( \pm 20) \\
71( \pm 11)\end{array}$ \\
\hline Heart rate $(\mathrm{bpm})$ & $69(16 / 44-150)$ & $71(11 / 44-100)$ \\
\hline $\begin{array}{r}\text { LVEF }(\% / \mathrm{sd}) \\
\text { At diagnosis } \\
\text { Most recent } \\
\end{array}$ & $\begin{array}{c}32( \pm 9) \\
40( \pm 11)\end{array}$ & $\begin{array}{c}31( \pm 9) \\
37( \pm 11)\end{array}$ \\
\hline $\begin{array}{l}\text { Aetiology } \\
\text { Ischemic } \\
\end{array}$ & $47(48 \%)$ & $43(47 \%)$ \\
\hline $\begin{array}{c}\text { Duration of } \mathrm{HF} \text { (days) } \\
\leq 2 \text { years } \\
>2 \text { years }\end{array}$ & $\begin{array}{c}1134(1312) \\
51(53 \%) \\
46(47 \%) \\
\end{array}$ & $\begin{array}{l}1095(938) \\
46(50 \%) \\
46(50 \%) \\
\end{array}$ \\
\hline \multicolumn{3}{|c|}{ Laboratory (median or mean/sd) } \\
\hline $\begin{array}{l}\text { NT proBNP }(\mathrm{ng} / \mathrm{L}) \\
\text { (median/Q1-Q3) }\end{array}$ & $\begin{array}{c}1115 \begin{array}{c}(410-1771) \\
(\mathrm{n}=77)\end{array} \\
\end{array}$ & $\begin{array}{c}825(360-2142) \\
(\mathrm{n}=69)\end{array}$ \\
\hline Sodium (mmol/L) & $140( \pm 2.7)$ & $139( \pm 5.7)$ \\
\hline Potassium (mmol/L) & $4.3( \pm 0.5)$ & $4.4( \pm 0.4)$ \\
\hline Creatinine (umol/L) & $110( \pm 32)$ & $108( \pm 37)$ \\
\hline GFR $\left(\mathrm{mL} / \mathrm{min} \times 1.73 \mathrm{~m}^{2}\right)$ & $\begin{array}{c}57( \pm 18) \\
(\mathrm{n}=64)\end{array}$ & $\begin{array}{c}58( \pm 19) \\
(\mathrm{n}=63)\end{array}$ \\
\hline \multicolumn{3}{|l|}{ Medication Class Adherence } \\
\hline ACE-I or ARB & $88(91 \%)$ & $85(92 \%)$ \\
\hline Beta-blocker & $91(94 \%)$ & $83(90 \%)$ \\
\hline
\end{tabular}




\begin{tabular}{|l|c|c|}
\hline MRA & $42(43 \%)$ & $49(53 \%)$ \\
\hline Other cardiac medication & & \\
\hline Diuretics & $79(81 \%)$ & $79(86 \%)$ \\
Thiazide & $5(5 \%)$ & $3(3 \%)$ \\
Digoxin & $14(14 \%)$ & $14(15 \%)$ \\
Statins/Lipid lowering agents & $54(56 \%)$ & $50(54 \%)$ \\
Nitrates & $15(15 \%)$ & $17(19 \%)$ \\
Anticoagulants & $54(56 \%)$ & $54(59 \%)$ \\
\hline
\end{tabular}

Table 2. Medication Class Adherence at baseline and 12 months

\begin{tabular}{|l|c|c|c|c|}
\hline & \multicolumn{2}{|c|}{ Primary Care } & \multicolumn{2}{c|}{ HF clinic } \\
\hline & Baseline (n=97) & Follow-up (n=85) & Baseline (n=92) & Follow-up (n=83) \\
\hline ACE/ARB & $88(91 \%)$ & $77(91 \%)$ & $85(92 \%)$ & $74(90 \%)$ \\
\hline Beta-blocker & $91(94 \%)$ & $79(93 \%)$ & $83(90 \%)$ & $76(93 \%)$ \\
\hline MRA & $42(43 \%)$ & $41(48 \%)$ & $49(53 \%)$ & $44(54 \%)$ \\
\hline
\end{tabular}

Table 3. GAI-3 total scores at baseline and 12 months per treatment group

\begin{tabular}{|l|c|c|c|}
\hline & $\begin{array}{c}\text { Primary Care } \\
\boldsymbol{\%}(\mathbf{9 5 \%} \mathbf{C I})\end{array}$ & $\boldsymbol{\%}(\mathbf{9 5 \%} \mathbf{C I})$ & \\
\hline GAI-3 total baseline* & $95.0(91.8-98.2)$ & $94.6(91.0-98.1)$ & 0.85 \\
\hline GAI-3 total 12 months* & $91.6(87.7-95.4)$ & $91.1(86.9-95.3)$ & 0.87 \\
\hline Difference & $-3.4(-5.6--1.3)$ & $-3.4(-6.0--.90)$ & 0.99 \\
\hline
\end{tabular}

* MRA corrected for NYHA class 
Table 4. Patient compliance in medication possession ratio (MPR) per medication class at 12 months

\begin{tabular}{|l|c|c|c|}
\hline & Primary Care & HF clinic & difference \\
\hline ACE-I/ARB & $93.5 \%(\mathrm{n}=51)$ & $95.2 \%(\mathrm{n}=53)$ & 0.67 \\
Beta-blocker & $93.5 \%(\mathrm{n}=57)$ & $94.9 \%(\mathrm{n}=56)$ & 0.42 \\
MRA & $87.1 \%(\mathrm{n}=23)$ & $93.3 \%(\mathrm{n}=26)$ & 0.28 \\
& & & 0.10 \\
\hline Average total score & $92.3 \%(\mathrm{n}=61)$ & $94.4 \%(\mathrm{n}=59)$ & \\
\hline
\end{tabular}

Table 5. Numbers and incidence rates of death and readmissions per treatment group

\begin{tabular}{|c|c|c|c|c|c|}
\hline & $\begin{array}{c}\text { Primary Care } \\
(n=97)\end{array}$ & IR/yr & $\begin{array}{c}\text { HF clinic } \\
(\mathrm{n}=92)\end{array}$ & IR/yr & $\begin{array}{l}\text { IR dif } \\
(95 \% \mathrm{CI})\end{array}$ \\
\hline Total number of deaths & 12 & 0.128 & 8 & 0.092 & $\begin{array}{c}-.036 \\
(-.133-0.061)\end{array}$ \\
\hline Cause of death & & & & & $\mathrm{P}=0.481$ \\
\hline CVA & 1 & & 1 & & \\
\hline Heart failure & 2 & & 2 & & \\
\hline Other $\mathrm{CV}$ disorders & 0 & & 1 & & \\
\hline Other non $\mathrm{CV}$ disorders & 6 & & 1 & & \\
\hline Unknown & 3 & & 3 & & \\
\hline $\begin{array}{l}\text { Total number of } \\
\text { readmissions for } \mathrm{HF}\end{array}$ & 8 & 0.082 & 7 & 0.076 & $\begin{array}{c}-0.006 \\
(-0.086-0.073) \\
P=0.882\end{array}$ \\
\hline $\begin{array}{l}\text { Total number of } \\
\text { readmissions CV }\end{array}$ & 5 & 0.052 & 6 & 0.065 & $\begin{array}{c}-0.014 \\
(-0.055-0.083) \\
P=0.710\end{array}$ \\
\hline $\begin{array}{l}\text { Total number of } \\
\text { readmission non-CV }\end{array}$ & 22 & 0.227 & 10 & 0.109 & $\begin{array}{c}-0.118 \\
(-0.234--0.002) \\
P=0.05\end{array}$ \\
\hline
\end{tabular}


Table 6. Non CV hospital readmissions in the Primary Care group and in the HF clinic group

\begin{tabular}{|c|c|c|}
\hline Reason for readmission (MeDRA code) & Primary Care (n) & HF clinic(n) \\
\hline Hypoglycaemia & 1 & - \\
\hline Hyperglycaemia & 1 & - \\
\hline Nausea and vomiting symptoms & 3 & 1 \\
\hline Asthenic conditions & 2 & 1 \\
\hline Electrolyte and fluid balance conditions & 1 & 1 \\
\hline Melaena & 3 & 1 \\
\hline Respiratory tract infections & 5 & - \\
\hline Bronchospasm and obstruction (COPD) & 1 & - \\
\hline Dyspnoea & 1 & - \\
\hline Gastrointestinal therapeutic procedures & - & 1 \\
\hline Abdominal and gastrointestinal infections & - & 1 \\
\hline Skin lesion excisions & 1 & - \\
\hline Ribfracture & - & 1 \\
\hline Lower limb fractures and dislocations & 1 & \\
\hline Bone related signs and symptoms & - & 1 \\
\hline Infectious arthritis & - & 1 \\
\hline Non-site specific procedural complications & 1 & - \\
\hline Inguinal hernia & 1 & - \\
\hline Poisoning and toxicity & - & 1 \\
\hline Total & 22 & $\mathbf{1 0}$ \\
\hline
\end{tabular}



Figure 1 Flow diagram; screening, randomization, follow-up and analyses
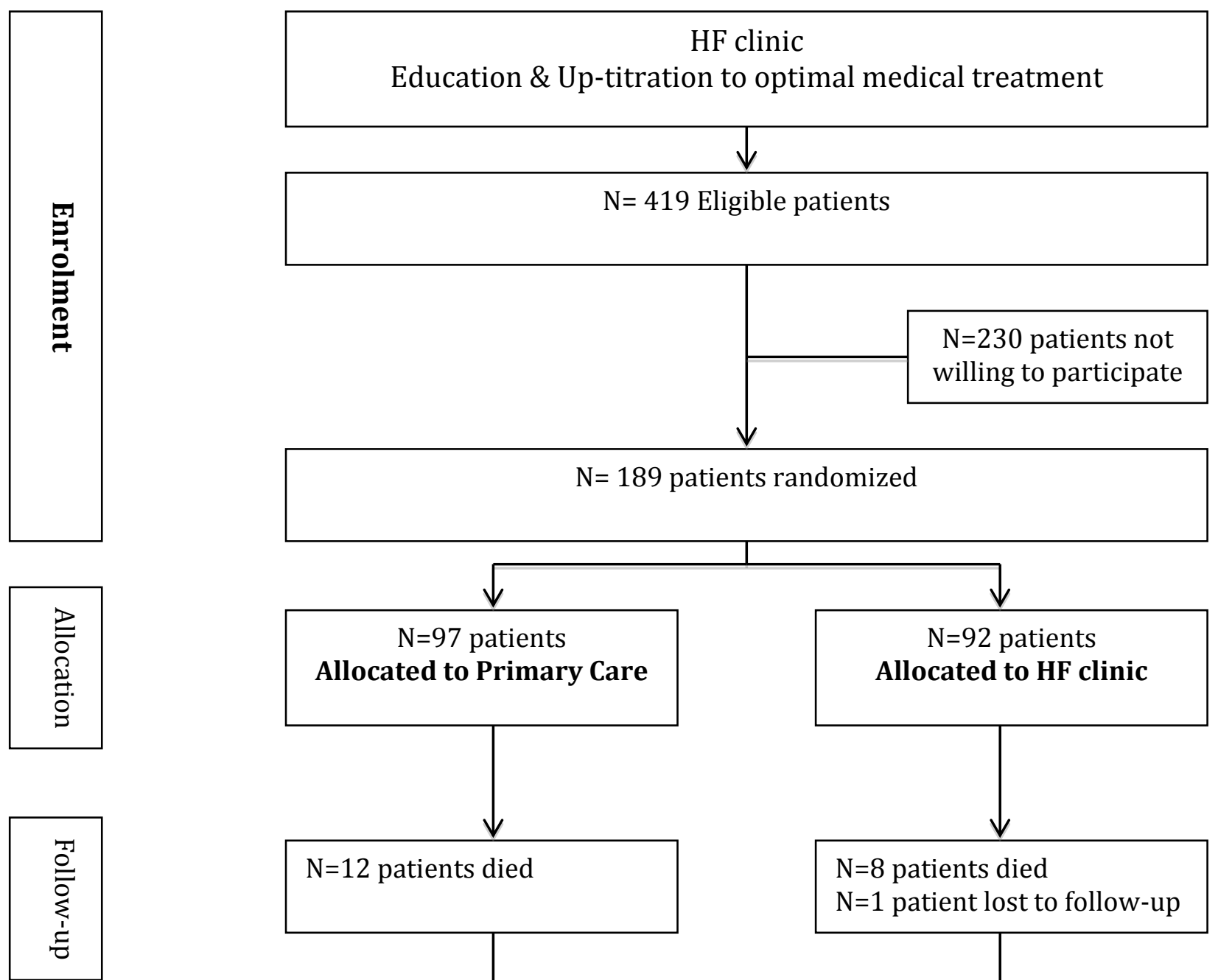

$\mathrm{N}=12$ patients died

$\mathrm{N}=8$ patients died

$\mathrm{N}=1$ patient lost to follow-up
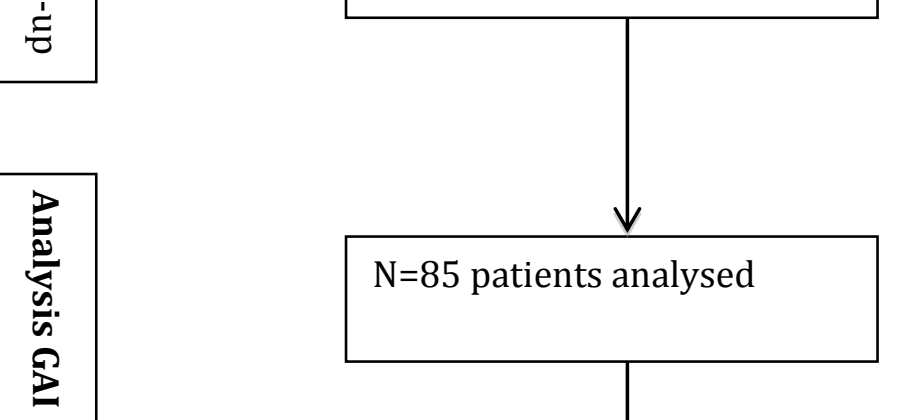

$\mathrm{N}=85$ patients analysed

$\mathrm{N}=83$ patients analysed
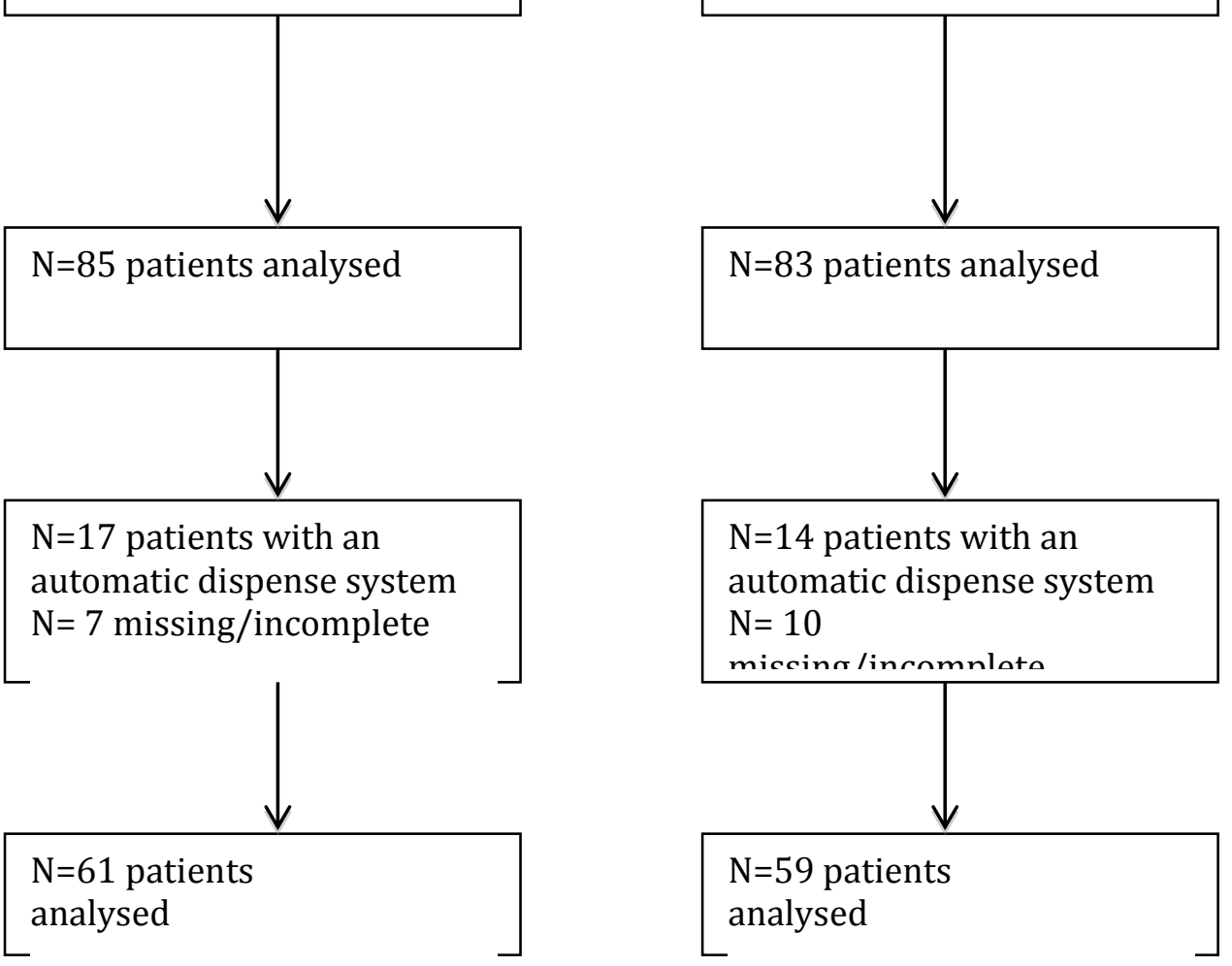

$\mathrm{N}=14$ patients with an automatic dispense system $\mathrm{N}=10$

miccina/inremnlata

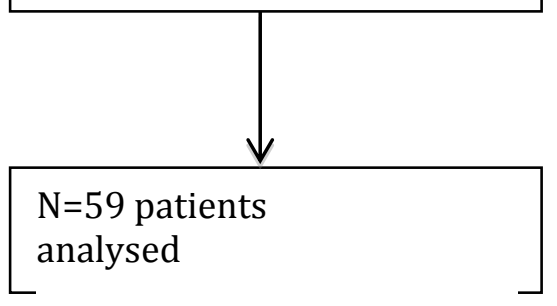

